\title{
Coronary Microvascular Injury in the COVID-19 Patient: The Need for Imaging Studies in Post-COVID-19 Cardiovascular Syndrome
}

\section{Paula Marcela Cuéllar-Pinzón, MD', María Paula Montes-Lozano, MD², Marco Antonio Suárez- Fuentes, $M D^{3}$, Miller Jesús Melo-Mora, $M^{4}$ and Michael Gregorio Ortega-Sierra, $M D^{5 *}$}

\author{
${ }^{1}$ School of Medicine, Fundación Universitaria Sanitas, Bogota, Colombia \\ ${ }^{2}$ School of Medicine, Universidad Metropolitana, Barranquilla, Colombia \\ ${ }^{3}$ School of Medicine, Universidad del Sinú, Cartagena, Colombia \\ ${ }^{4}$ School of Medicine, Escuela Latinoamericana de Medicina en Cuba, La Habana, Colombia \\ ${ }^{5}$ School of Medicine, Corporación Universitaria Rafael Nuñez, Cartagena, Colombia
}

*Corresponding author: Michael Gregorio Ortega-Sierra, School of Medicine, Corporación Universitaria Rafael Nuñez, Cartagena, 130004, Colombia

\section{Keywords \\ Coronary disease, COVID-19, Post-COVID-19 cardiovascular syndrome, Post-COVID-19 syndrome, Cardiac imaging techniques}

The COVID-19 pandemic has generated numerous questions about the pathophysiology of the acute phase of this disease, and as time goes by, also of the chronic phase, known as post-COVID-19 syndrome [14]. Although the neurological phenotype (post-COVID 19 neurological syndrome) is the most debated [1,2], the evidence points to the fact that the main manifestations of post-COVID 19 patients, regardless of disease severity, are dyspnea, fatigue, tachycardia, and difficulties in performing activities of daily living [5]. This raises alarms about the presence of persistent target organ injury since the acute phase of COVID-19, or whether previous inflammation may have decompensated the mechanisms that some organs perform in the face of chronic disorders. There is evidence that has reported the compromise of the endothelium and myocardium during the acute phase of the disease, with the presence of previous heart disease being considered a risk factor for severe disease and death [6].
Interestingly, Drakos, et al. [7] evaluated coronary microvascular disease in COVID-19 patients by cardiovascular magnetic resonance imaging, showing that patients who had COVID-19 had significantly reduced global myocardial perfusion reserve (2.73 [2.10 - $4.15-11$ ] vs. 4.82 [3.70-6.68], $p=0.005)$, significantly increased coronary sinus flow at rest $(1.78 \mathrm{ml} / \mathrm{min}$ [1.19$2.23 \mathrm{ml} / \mathrm{min}$ ) vs. $1.14 \mathrm{ml} / \mathrm{min}$ [0.91-1.32 $\mathrm{ml} / \mathrm{min}$ ], $p=$ $0.048)$, and reduced coronary sinus flow during stress activity $(3.33 \mathrm{ml} / \mathrm{min}[2.76-4.20 \mathrm{ml} / \mathrm{min}$ ) vs. $5.32 \mathrm{ml} / \mathrm{min}$ [3.66-5.52 $\mathrm{ml} / \mathrm{min}$ ], $\mathrm{p}=0.05$ ), compared to controls [7]. Based on the above, the authors concluded that there is cardiac microvascular injury in COVID-19 patients, which may trigger major cardiovascular events in the post-COVID-19 phase, and this is one of the reasons that would explain the persistence of fatigue and dyspnea during this phase [7].

Another study that supports the persistence of endothelial dysfunction, but using another vascular parameter (flow-mediated dilation), is that of Ambrosino, et al. [8], who carried out a case-control study with 133 patients where they found that a significantly lower flow-mediated dilation in postCOVID 19 patients as compared to controls $(3.2 \% \pm 2.6$

Citation: Cuéllar-Pinzón PM, Montes-Lozano MP, Suárez-Fuentes MA, Melo-Mora MJ, Ortega-Sierra MG (2022) Coronary Microvascular Injury in the COVID-19 Patient: The Need for Imaging Studies in Post-COVID-19 Cardiovascular Syndrome. Int Arch Cardiovasc Dis 5:049. doi.org/10.23937/26433966/1710049

Accepted: January 06, 2022: Published: January 08, 2022

Copyright: (C) 2022 Cuéllar-Pinzón PM, et al. This is an open-access article distributed under the terms of the Creative Commons Attribution License, which permits unrestricted use, distribution, and reproduction in any medium, provided the original author and source are credited. 
vs. $6.4 \% \pm 4.1 p<0.001)$, confirmed when stratifying the study population according to age and major clinical variables. Among cases, females exhibited significantly higher flow-mediated dilation values as compared to males $(6.1 \% \pm 2.9$ vs. $2.5 \% \pm 1.9, p<0.001)$. Among post-COVID 19 patients, flow-mediated dilation showed a direct correlation with arterial oxygen tension $(0.247$, $p=0.004)$, forced expiratory volume in $1 \mathrm{~s}(0.436, p<$ $0.001)$, forced vital capacity $(0.406, p<0.001)$, and diffusing capacity for carbon monoxide $(0.280, \mathrm{p}=$ 0.008). In conclusion, post-COVID-19 syndrome was a major and independent predictor of flow-mediated dilation values $(\beta=-0.427, p<0.001)$ [8]. This allows us to understand that although the study investigated pulmonary vascular dynamics and some respiratory parameters, the endothelial damage could be the same and can be correlated with the mechanism of lung-heart circulation [7-9].

It is valid then, even to raise the question of whether there is silent myocarditis in the patient with asymptomatic COVID-19, which through compensatory mechanisms does not develop symptoms, but leaves a trace in the vascular and cardiac territory? clearly, in the patient with cardiovascular risk factors, we should inquire more quickly through translational research on the degree of tissue inflammation or activation of profibrogenic or proatherogenic signaling pathways, which alter cardiac dynamics [10].

This should force the general practitioner and the cardiologist to ask themselves, what is the status of the patient with a history of cardiovascular disease who is in the post-COVID-19 phase, regardless of the presence of symptoms or not? The history of ischemic heart disease, heart failure (especially with reduced ejection fraction) or any other condition that may generate hemodynamic or metabolic alterations such as hypertension or diabetes mellitus $[3,10]$, should be interpreted in clinical practice as warning signs in the patient with possible impairment of functional capacity and survival due to a possible major cardiovascular event during the postCOVID phase [5-9].

From this, lies the importance of using cardio-imaging such as cardiovascular magnetic resonance imaging, which allows an accurate, broad and deep evaluation of cardiac functionality and structure, and provides information on the suggestive existence or absence of myocardial compromise secondary to COVID-19 [79], which may decrease the functional capacity of the individual, increase the risk of decompensation (for example in the patient with heart failure) or death, or re-evaluate therapeutic plans based on the findings and the mechanisms of action of the most appropriate drugs for each case. Prospective multicenter studies are needed to define cutoff scores for hemodynamic and structural parameters to control the burden of cardiovascular disease that is expected in this group of patients.

\section{Funding}

None.

\section{Conflicts of Interest}

None.

\section{References}

1. González-Herazo MA, Silva-Muñoz DC, GuevaraMartínez PA, Lozada-Martinez ID (2021) Post-COVID 19 Neurological syndrome: A fresh challenge in neurological management. Neurol Neurochir Pol 55: 413-414.

2. Camargo-Martínez W, Lozada-Martínez I, EscobarCollazos A, Navarro-Coronado A, Moscote-Salazar L, et al. (2021) Post-COVID 19 neurological syndrome: Implications for sequelae's treatment. J Clin Neurosci 88: 219-225.

3. Ståhlberg $M$, Reistam $U$, Fedorowski A, Villacorta $H$, Horiuchi Y, et al. (2021) Post-covid-19 tachycardia syndrome: A distinct phenotype of post-acute covid-19 syndrome. Am J Med 134: 1451-1456.

4. Ocher RA, Padilla E, Hsu JC, Taub PR (2021) Clinical and laboratory improvement in hyperadrenergic postural orthostatic tachycardia syndrome (POTS) after covid-19 infection. Case Rep Cardiol 2021: 7809231.

5. Anaya JM, Rojas M, Salinas ML, Rodríguez Y, Roa G, et al. (2021) Post-covid syndrome. A case series and comprehensive review. Autoimmun Rev 20: 102947.

6. Camargo-Martinez WC, Lozada-Martinez ID, Osorio AA, Moscote-Salazar LR, Janjua T (2021) Giant inverse T-wave in a patient with covid-19. J Transl Crit Care Med 3: 3.

7. Drakos S, Chatzantonis G, Bietenbeck M, Evers G, Schulze $A B$, et al. (2021) A cardiovascular magnetic resonance imaging-based pilot study to assess coronary microvascular disease in covid-19 patients. Sci Rep 11: 15667.

8. Ambrosino P, Calcaterra I, Molino A, Moretta P, Lupoli R, et al. (2021) Persistent endothelial dysfunction in post-acute covid-19 syndrome: A case-control study. Biomedicines 9: 957.

9. Huang L, Zhao P, Tang D, Zhu T, Han R, et al. (2020) Cardiac involvement in patients recovered from covid-2019 identified using magnetic resonance imaging. JACC Cardiovasc Imaging 13: 2330-2339.

10. Yan Z, Yang M, Lai CL (2021) Long covid-19 syndrome: A comprehensive review of its effect on various organ systems and recommendation on rehabilitation plans. Biomedicines 9: 966. 